\title{
Representation and reality
}

It is a truism that art, by representing the world, changes the way we see it. Alexander Eisenschmidt's exploration of August Endell's eulogy of the modern city (pp. 71-79) offers a perfect example of this: 're-framed', the apparent chaos and confusion brought on by modernisation could be seen as thrilling manifestations of a dynamic new culture. Technological changes, such as the invention of photography, are increasingly bound up in such major changes in 'ways of seeing', and rarely has this been more apparent than in the transformations brought by the change from drawing-board and T-square to PC and plasma screen.

With the widespread diffusion of computer-aided design and, increasingly, manufacturing systems, the interplay between the conception, representation and construction of architecture has never been more complex. Academic and journalistic attention, not surprisingly, tends to concentrate on the innovative, where form-generating software or the 'reverse engineering' techniques pioneered by Frank Gehry permit the creation of increasingly sensational - and, in the eyes of some, sensuous - forms.

At the level of most architectural practices, however, the impact of CAD is probably just as pervasive but less easy to pin down. On a negative note, perhaps, it is becoming apparent in the tendency of many modern buildings not merely simply to resemble the representations made of them, but to seem less real than the glamorous 'photorealistic' renderings used to promote them. In part this is due to the gap between the growing sophistication of our means of representation and a corresponding visual impoverishment that results directly from the means of everyday construction. Crudely assembled rather than carefully built, and generally devoid of the close-up pleasures of fine materials that Otto Wagner and Adolf Loos looked to as compensation for the disappearance of craftsmanship, modern buildings rarely offer those multi-scaled pleasures, from far away and close to, that Ruskin described as 'ornament'.

In the wider historical context explored by Penelope Haralambidou in her thoughts on Marcel Duchamp's last work, Etant donnés (pp. 36-51), the growing disjuncture between representation and reality may ultimately be seen to stem from the Renaissance discovery - or invention, or re-discovery, according to your art-historical take on the issue of perspective, and the subsequent reinforcement by photography of a view of space as a continuum bounded by flat planes. Seen stereoscopically through a pair of peepholes the mysterious diorama of Duchamp's Etant donnés seems as hyper-real as many a computer rendering, but unlike them it also induces vivid tactile and kinaesthetic sensations. And these, as Haralambidou points out, can also be created by pairs of stereoscopic images which could now readily be generated by computers, and used to highlight the impoverishment of architectural intentions that many flashy perspectives and glamorous flies-through so artfully conceal. 


\section{architectural research quarterly}

\section{Subscribe now for 2007}

Innovative in conception, unique in breadth and generously illustrated, this pace-setting quarterly publication from Cambridge University Press links, on a global scale, the worlds of architectural practice and research. arq regularly includes extensive peer-reviewed sections on design, history, theory, construction, environmental design, information technology and practice - as well as structures, urbanism and documents. These are supplemented by letters, reports, reviews, a directory of specialist research centers and consultancies and an annual index. Each issue opens with a leader and closes with insight, a personal end-piece. In its ten year history, arq has published work from all over the world: from Chile to Sweden and from Japan to the Netherlands - with a strong representation from the United Kingdom and United States. arq, like architecture itself, is all-embracing and written by and for both practitioners and academics. It provides an outlet for all those who wish to disseminate their work to an international audience.
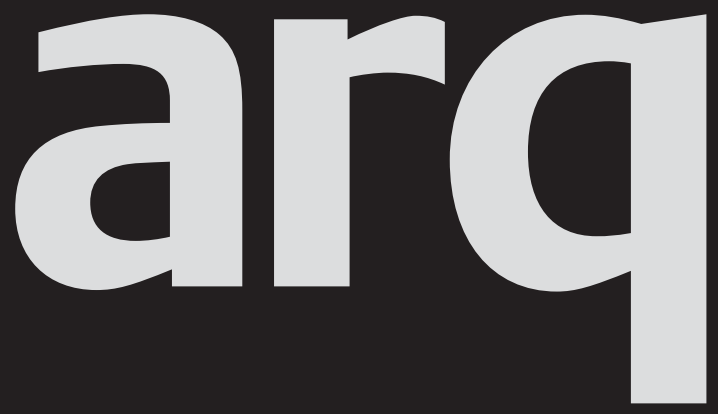

Please enter my subscription to arq: architectural research quarterly, volume 11, 2007 $\square £ 156 / \$ 252$ institutions print and electronic $\square £_{30} / \$ 50$ students print only

$\square$ £42/\$64 individuals print only

EU residents only. VAT may be payable at your local rate if not registered.

Our VAT registration number: GB 214141614 If registered, your VAT registration no:

Total subscription payment $£ / \$$ EU residents only, if not registered add VAT at appropriate rate

Canadian residents, add 7\% GST \$

Total $\mathbf{E} / \$$

Name

Address

Payment enclosed

Cheque in sterling or US dollars

(payable to Cambridge University Press)

Credit Card - VISA | MasterCard | American Express (delete where applicable)

Card no

Expiry date

Signature

Photocopy this page and send your order to:

Journals Customer Services, Cambridge University Press, The Edinburgh Building, Cambridge, CB2 8RU, UK

$\mathrm{T}+44(0) 1223326070$

$\mathrm{F}+44(0) 1223315052$

E journals@cambridge.org

or in USA, Canada and Mexico send to:

Cambridge University Press, 32 Avenue of the

Americas, New York NY 10013-2473, USA

T (914) 9379600

F (914) 9374712

E journals_subscriptions@cup.org 